日臨外会誌 $78(10), 2197-2201 ， 2017$

原著

肺癌患者の中心静脈ポート抜去に対するベバシズマブ投与の影響

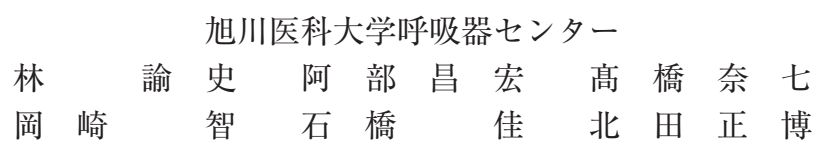

肺癌や大腸癌, 乳癌などの治療に用いられるベバシズマブ（Bev）はその作用機序か ら創治癒不全を誘発する。皮下埋め込み型中心静脈ポート（CVP）は薬剂投与や補液 目的に留置されるが, 合併症による抜去が問題となる. Bev投与やその他因子がポート 抜去に影響するか検討した。 2008年10月～2016年 7 月の進行・再発肺癌148例を対象と した，合併症による抜去は23例で，内訳は感染11例，創哆開による露出10例，閉塞 2 例 であった．若年，Bev投与でCVP抜去に至る例が多かった．CVP使用開始までの期間 は抜去群10.0日, 非抜去群13.3日であり, 抜去群の方が短い傾向であった。 術後200日で のCVP留置率はBev投与あり53.1\%, なし93.4\%であった. CVP留置の際は, Bev投与 による抜去の危険性について説明し，CVP使用までの期間を長くとることで，抜去例 を減少させられる可能性が示唆された.

索引用語：中心静脈ポート, ベバシズマブ, 肺癌

緒言

進行・再発の非扁平上皮肺癌に対し, プラチナ併用 化学療法にベバシズマブ（Bevacizumab, Bev）を追 加することで全奏効率の上昇, progression free survivalの延長が示されており, Bev使用例が増加して いる. 皮下埋め达み型中心静脈ポート (central venous access port, CVP) は薬剤投与や補液のためし ばしば留置されるが, 合併症のため抜去に至る症例が あり, 原疾患の治療継続や患者の quality of life (QOL) に支障をきたす．Bevは創治癒遅延を起こすとされて おり，Bev投与やその他因子がポート抜去に影響する 可能性について検討した.

\section{対象および方法}

2008年10月～2016年 7 月の進行・再発肺癌患者で, CVPを留置した連続148例，148CVPを対象とした。 全例， $1 \%$ キシロカインで局所麻酔後にバードスリム ポート ${ }^{\circledR}$ (メディコン) を留置した. 術前の消毒は $10 \%$ ポピドンヨード液を使用した. 閉創は 3-00吸収系 で皮下埋没縫合を行った後, 表皮は 4-0ナイロン糸

2017年 5 月 1 日受付 2017 年 7 月 26 日採用

〈所属施設住所〉

干078-8510 旭川市緑が丘東 2 条 1-1-1
による縫合あるいは皮膚表面接着剂（ダーマボンド®， Echicon）を使用した。ナイロン糸の抜糸は基本的に 術後 1 週間後を目安としたが, 創状態により抜糸を数 日間遅らせた。皮膚表面接着剤は除去せず，自然に剥 がれ創治癒が得られるまで塗布したまま経過観察し た. 術後はセフェム系第 1 世代の cefaclorを 3 日間内 服投与した。感染は, 創周囲の発赤や膿汁の流出, 培 養での感染源の同定, 発熱などを考慮しつつ総合的に 判定した. 感染を伴わない創の離開のみを創哆開と判 定した。なお，CVPからの採血や輸血は施行しない 方針とした，検討項目は，CVP留置術後の観察期間， CVP使用開始までの期間, 年齢, 性別, body mass index (BMI), 術前 performance status (PS), 糖尿 病の有無, 使用目的 (化学療法, 補液, Bev使用), 手術時間，閉創法，穿刺部位とした。本検討では， CVP感染, 創哆開, 閉塞といった合併症によるCVP 抜去のみを『CVP抜去』と定義し，これを抜去群（remove群：R群）とした，その他の死亡時 CVP留置例 を含む非抜去例と治療終了によるCVP抜去例を合わ せて留置・治療完遂群 (remained or completion of the treatment群 : RCT群) として，2 群間の比較検 討を行った，RCT群における死亡，治療完遂による CVP抜去は, イベントではなく中断として扱った. 
統計学的解析には統計解析ソフトウエアの JMP ${ }^{\circledR} 10$ (SAS Institute Inc., Cary, NC, USA) を使用し, 2 群間の比較には $\chi^{2}$ 検定と $\mathrm{t}$ 検定, Fisherの直接確率 検定を用い，留置率の差の検定にはKaplan-Meier 法 を用いた。各因子間の関連を除外し，独立した因子を 選択するためにロジスティック回帰分析を行った。な お, 数值データ (年齢, 術後平均経過観察期間, CVP 使用開始までの期間，BMI，手術時間）は連続変数,

\section{Table 1 Patient characteristics}

\begin{tabular}{|c|c|}
\hline Number of cases & 148 \\
\hline Age (mean \pm S.D.) & $65 \pm 9$ \\
\hline Sex (cases, Male / Female) & $104 / 44$ \\
\hline Follow up (mean, day) & $208 \pm 253$ \\
\hline First use (mean, day) & $12.8 \pm 12.0$ \\
\hline BMI & $21.9 \pm 3.9$ \\
\hline PS & $0.61 \pm 0.91$ \\
\hline Diabetes mellitus (cases, Yes / No) & $30 / 118$ \\
\hline \multicolumn{2}{|l|}{ Purpose (cases) } \\
\hline Chemotherapy & 118 \\
\hline Parenteral nutrition & 37 \\
\hline Bevacizumab & 40 \\
\hline Operation time (min) & $22.4 \pm 10.1$ \\
\hline Closure (cases, Dermabond / Nyron) & $109 / 39$ \\
\hline \multicolumn{2}{|l|}{ Position (cases) } \\
\hline Subclavian & 123 \\
\hline Femoral & 22 \\
\hline Jugular & 3 \\
\hline Removal (cases, Yes / No) & $23 / 125$ \\
\hline
\end{tabular}

それ以外はカテゴリー変数として取り扱った. $\mathrm{P}<$ 0.05で有意差ありと判定した。

\section{結 果}

患者背景を Table 1に示す。全例の平均年齢は65歳 で，男104例，女44例，術後平均観察期間は208日， CVP使用開始までの期間は 12.8 日であった。平均 BMI は21.9, 平均PSは0.61, 糖尿病合併は30例であった。 使用目的は化学療法118例，補液37例，Bev 40例であ った（重複あり）。平均手術時間は19.4分，閉創は皮 膚表面接着剂109例，ナイロン39例，穿刺部位は鎖骨 下が123例，鼠経 22 例，内頸 3 例であった．合併症に よる抜去は23例で，内訳は感染11例，創哆開による露 出10例，閉塞 2 例であった（Table 2).

Table 2 Outcomes of CVP placement

\begin{tabular}{|c|c|}
\hline & Cases \\
\hline Remained and completed the treatment & 125 \\
\hline Completion of the treatment & 2 \\
\hline Died & 26 \\
\hline Remained & 97 \\
\hline Removed by complications & 23 \\
\hline Infection & 11 \\
\hline Exposure & 10 \\
\hline Obstruction & 2 \\
\hline
\end{tabular}

Table 3 Risk factors related to CVP removal

\begin{tabular}{|c|c|c|c|}
\hline & $\begin{array}{c}\mathrm{R} \\
(\mathrm{n}=23)\end{array}$ & $\begin{array}{c}\mathrm{RCT} \\
(\mathrm{n}=125)\end{array}$ & $\mathrm{P}$ value \\
\hline Age (mean \pm S.D. $)$ & $60 \pm 11$ & $65 \pm 8$ & $<0.05$ \\
\hline Sex (cases, Male / Female) & $15 / 8$ & $89 / 36$ & 0.56 \\
\hline Follow up (mean, day) & $160 \pm 290$ & $217 \pm 246$ & 0.32 \\
\hline First use (mean, day) & $10.0 \pm 5.6$ & $13.3 \pm 12.8$ & 0.23 \\
\hline Body Mass Index & $23.0 \pm 2.9$ & $21.7 \pm 4.0$ & 0.13 \\
\hline Performance status & $0.61 \pm 0.84$ & $0.61 \pm 0.92$ & 0.95 \\
\hline Diabetes mellitus (cases, Yes / No) & $1 / 22$ & $29 / 96$ & $<0.05$ \\
\hline \multicolumn{4}{|l|}{ Purpose (cases, Yes / No) } \\
\hline Chemotherapy & $21 / 2$ & $97 / 28$ & 0.13 \\
\hline Parenteral nutrition & $3 / 20$ & $34 / 91$ & 0.15 \\
\hline Bevacizumab & $16 / 7$ & $24 / 101$ & $<0.05$ \\
\hline Operation time $(\min )$ & $19.4 \pm 6.9$ & $23.0 \pm 10.5$ & 0.12 \\
\hline Closure (cases, Dermabond / Nyron) & $19 / 4$ & $90 / 35$ & 0.29 \\
\hline Indwelling location (cases) & & & 0.08 \\
\hline Subclavian & 22 & 101 & \\
\hline Others & 1 & 24 & \\
\hline
\end{tabular}

$\mathrm{R}$ : removed group, $\mathrm{RCT}$ : remained and treatment-completed group. 
Table 3に, CVP抜去の有無と各因子間の t検定（数 值変数)， $\chi^{2}$ 検定あるいはFisherの直接確率法による 検定（カテゴリー変数）の結果を，Fig. 1にはロジス ティック回帰分析によるCVP抜去に対する各因子の オッズ比を示す。単変量解析（Table 3) で, R 群 (23 例）と RCT群（125例）の間で有意差を認めたのは年 齢（R群60歳， RCT 群65歳），糖尿病なし（R群96\%,
RCT群77\%)，Bev投与あり（R群69.5\%, RCT群19.2 $\%)$ ，鎖骨下静脈穿刺であった。多変量解析（Fig. 1) では，高年齢，高BMI，糖尿病なし，Bev投与あり， 鎖骨下静脈穿刺が有意であったＣＶＰ使用開始まで の期間は R 群10.0日， RCT 群13.3日であり， R 群の方 が短い傾向であった．糖尿病ありと弱い負の相関が見 られたのは化学療法の実施のみであった（相関係数 :

\section{Age \\ Sex: Male \\ Follow up \\ First use \\ BMI}

PS: 2-4

Diabetes mellitus

Chemotherapy

Parenteral nutrition

Bevacizumab

Operation time

Closure: Dermabond

Position: Subclavian
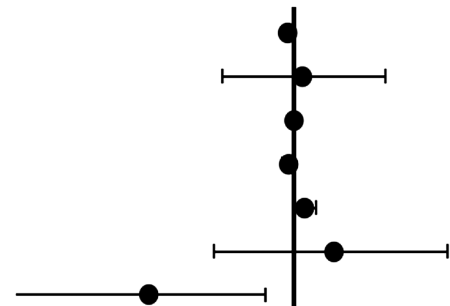

\section{(n)}

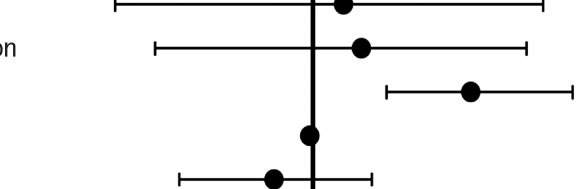

an

0.01

0.1

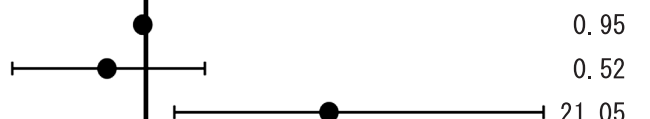

0.52

\begin{tabular}{cccc} 
Odds ratio & upper & lower & $P$ value \\
\hline 0.90 & 0.82 & 0.97 & $<0.05$
\end{tabular}

$\begin{array}{llll}1.15 & 0.30 & 4.58 & 0.84\end{array}$

1.00

0.99

1.00

0.06

0.92

0.83

1.00

0.10

1.20

1. 01

1. 45

$<0.05$

1.95

0.27

12. 95

0.49

0.09

0.00

0.63

$<0.05$

1. 66

0.04

45. 80

0.77

2. 25

0.07

35.06

0.58

13. 75

3. 42

74. 78

$<0.05$

0.87

1.03

0.251

0. 11

2. 69

0.421

1. 60

742. 44

$<0.05$

\section{Odds Ratio}

Fig. 1 Multivariate analysis with logistic regression.

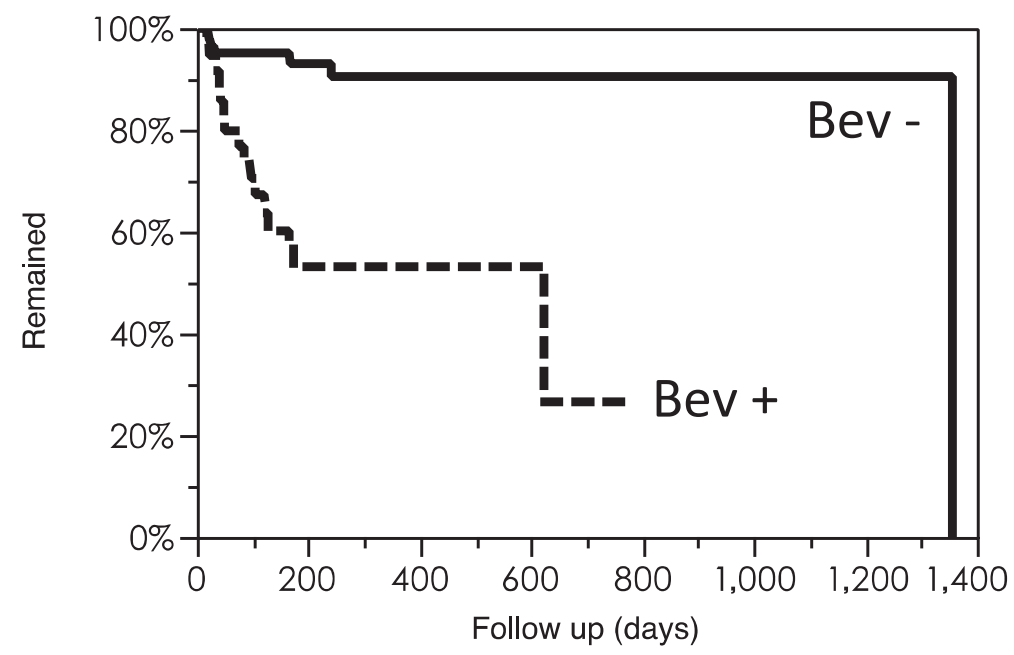

Fig. 2 Relationship between bevacizumab therapy and CVP indwelling ratio. 
-0.164). 術後200日時点での, 合併症に起因するCVP 抜去に至らなかった症例は，Bev投与あり $53.1 \%$ ，な し93.4\%であった（P<0.05）（Fig. 2). Bev使用例40 例に限定したR 群 (16例) とRCT 群 (24例) について, CVP使用開始までの期間を検討したところ， R 群は平 均11.2日, RCT群は17.1日であった $(\mathrm{P}=0.28)$. 経過 中に死亡イベントを 24 例認めたが，Bev投与による死 亡率の差は認めなかった $(\mathrm{P}=0.125)$.

\section{考察}

肺癌や大腸癌, 乳癌などの治療に用いられる Bevな どの抗VEGF薬は血管内皮細胞のアポトーシスを誘 導し，腫瘍血管の新生を抑制することで抗腫瘍効果を 発揮する. その作用機序から創治癒不全を誘発するこ とが考えられ，アバスチン特定使用成績調査1 ${ }^{1}$ におい て，Bev投与例のうち40例 $(1.48 \%$ ）で創治癒遅延に よる合併症があり，そのうち28例がCVP関連であっ たと報告されている，現在，薬剤投与や補液のため広 くCVPが用いられているが，人工物であるが故に感 染など合併症も多く，抜去に至ると原疾患に対する治 療継続が困難となり，また患者のQOLも低下する. CVP抜去に至る因子についてはこれまでも様々な報 告がなされているが, Bev投与との関連性を報告した 論文は少なく, さらに進行・再発肺癌患者に限定した 検討は現時点で医学中央雑誌, PubMedで検索した限 り存在しないため, 本検討を計画した。

本検討では, 術後平均経過観察期間208日で, 合併 症により23例（15.5\%）がCVP抜去に至った。これは 術後平均経過観察期間157日での本邦報告例 ${ }^{2)}$ の抜去 率 $32 \%$ よは良好であったが, それでも高率であり, 改善が必要である。過去の報告での抜去要因は感染が 最も多く23), 他に栄養・補液目的の投与や高齢, PS 不良などがリスク因子として報告されている2)。本検 討では若年・糖尿病非合併例でのCVP抜去例が多い 傾向であったが, 若年・糖尿病合併例では化学療法が 施行されている頻度が高く，その影響が考えられる. 穿刺部位においても有意差が認められたが, これは鎖 骨下静脈穿刺を第一選択としており，他部位に比べ頻 度が高いためと考えられる.ただし, 本検討で若年齢・ 糖尿病非合併・鎖骨下静脈穿刺でCVP抜去が多いこ とに関する明確な要因は不明であり，今後症例を重ね 検討する必要があると考える。

今回，われわれが注目したBevについては，使用例 の増加とともに創哆開の報告が増加している. Kriegel ${ }^{4)}$ は，Bev非投与例での創哆開によるCVP抜去
率は $0.19 \%$ であったのに対し，Bev投与例では $4.76 \%$ と，有意にBev投与が創哆開やCVP抜去に関与して いると報告している．従って，Bev投与時には創哆開 に注意すべきである。

CVP関連の合併症を起こさないためには，様々な 対策が考えられる．CVPは全身状態不良の患者に留 置されることが多く，改善が難しいことがしばしばで あるため, それ以外の抜去要因に対する対策が重要と なるままず, 感染については, CDCガイドライン5)に 基づいた感染対策を行うことが重要である。その他の 報告として良田ら $\left.{ }^{6}\right)$ は，自施設のCVP感染率が $4.5 \%$ と既報告に比べ低い要因として，手術時に電気メスを 使用しないことで虚血を避けているためと考察してい るが，全体の $3.5 \%$ で血腫除去や圧迫止血を要してお り，手技として一般的ではない，閉創法について，わ れわれはナイロン糸で縫合した場合, 術後 1 週間以降 に創状態を観察しつつ抜系を行っている。ただしょ り創の張力が長期間維持される皮膚表面接着剂を使用 しても，CVP抜去頻度に有意差はないことから，ナ イロン糸の抜糸を遅らせることは創哆開対策としては 有用ではなく, むしろ感染のリスクが高まると考える.

本検討では, Bev投与例に限定した場合においても， CVP抜去に至った症例はBev投与開始までの期間が 短い傾向にあった，ただし有意差はなく，正確な $\mathrm{Bev}$ 安全投与開始期間は推定できなかった，Bevによる創 治癒不全について, Erinjeriら ${ }^{7)}$ は, Bev投与時期と 創哆開の関連について報告している。すなわち, CVP 留置後 7 日以内にBevを投与した例は，7 日以降に投 与した例と比較して，創哆開の相対リスクが 11.5 と有 意に上昇すると報告した。同様にKriegel ら ${ }^{4)}$ は Bev 非投与例での創哆開は $0.19 \%$ であったが，Bev投与例 では $4.76 \%$ で起こり，7 日以内にBevを投与した場合 $8.6 \%$ で創哆開を起こしたと報告している. 従って, Bev投与が必要な症例では, 少なくとも Bevの使用を CVP留置後 7 日以降にすることで創哆開のリスクを 軽減できる可能性がある.

CVP留置術前のBev投与については, Erinjeri ${ }^{7)}$ は無関係，Zawackiら ${ }^{8)}$ は創哆開の頻度が高まると報 告しており一定ではない. 本検討の後, 当科でのBev 投与予定患者について, 術前後少なくとも 1 週間は Bev投与を行わない方針としたところ創哆開例が減少 しており，可能であればCVP留置の周術期はBevの 投与を避けるべきであると考える. 
結語

Bev使用はCVP抜去に至る最も重要な因子であっ た。CVP留置の際は，Bev投与による抜去の危険性 について説明し，CVP使用までの期間を長くとるこ とで, 抜去例を減少させられる可能性が示唆された。 本論文の主旨は, 第117回日本外科学会定期学術集 会（2017年 4 月，横浜）で発表した.

利益相反：なし

\section{文献}

1）中外製薬.アバスチン特定使用成績調查最終解析 結果. (Accessed May 1, 2017, at https://chugaipharm.jp/hc/ss/pr/drug/ava_via0100/report/ sdvs/PDF/20170228_ava_tokuteiResult.pdf)

2）笹田伸介, 右近 圭, 佐藤幸雄 : 完全埋め込み型 中心静脈ポート感染における危険因子の検討. 外 科 $2014 ; 76: 1148-1151$

3）竹原清人, 田中屋宏爾, 森廣俊昭他 : 埋め込み型 中心静脈ポート感染の起因菌とリスク因子に関す る検討. 日外感染症会誌 $2011 ； 8 ： 699-703$

4) Kriegel I, Cottu PH, Fourchotte V, et al : Wound healing and catheter thrombosis after implantable venous access device placement in 266 breast cancers treated with bevacizumab therapy. Anticancer Drugs $2011 ; 22$ : $1020-1023$

5) O'Grady NP, Alexander M, Burns LA, et al : Guidelines for the prevention of intravascular catheter-related infections. Am J Infect Control $2011 ; 39:$ S1 - 34

6）良田大典, 松島英之, 中村有佑他：皮下埋没型中 心静脈カテーテル留置術のアプローチ方法. 日臨 外会誌 $2016 ; 77: 2138-2142$

7) Erinjeri JP, Fong AJ, Kemeny NE, et al : Timing of administration of bevacizumab chemotherapy affects wound healing after chest wall port placement. Cancer $2011 ; 117: 1296-1301$

8) Zawacki WJ, Walker TG, DeVasher E, et al : Wound dehiscence or failure to heal following venous access port placement in patients receiving bevacizumab therapy. J Vasc Interv Radiol $2009 ; 20: 624-627$

\title{
EFFECTS OF BEVACIZUMAB THERAPY FOR CENTRAL VENOUS ACCESS PORT REMOVAL IN LUNG CANCER PATIENTS
}

\author{
Satoshi HAYASHI, Masahiro ABE, Nana Takahashi, \\ Satoshi OKAZAKI, Kei ISHIBASHI and Masahiro KITADA \\ Respiratory Center, Asahikawa Medical University
}

Bevacizumab (Bev) is widely used in the patients with lung, colon, and breast cancer, but it is associated with wound dehiscence owing to its mechanizms of action. Central venous access port devices (CVPs) are used for several purposes such as infusion of chemotherapy and parenteral nutrition, but problms lie in the removal of CVP due to complications. We have studied whether Bev therapy and other factors affect the CVP removal. We retrospectively analyszed 148 progressive and recurring lung cancer patients who received CVP inplantation in our hospital between Octover 2008 and July 2016. There were 23 cases of CVP removal due to complications, with 11 cases of infection, 10 cases of wound dehiscence and two cases of obstruction. Juvenile Bev treatment patients often resulted in CVP removal. The median period until the start of CVP use was 10.0 days in the removal group and 13.3 days in the non-removal group, and the removal group tended to show ealier start. The CVP indwelling rate at the postoperative day 200 was $53.1 \%$ with Bev administration, versus $93.4 \%$ without. At the time of CVP placement, this study suggest that if we prolong the start of CVP use explaining the increasing risk of complications related to CVP by Bev therapy, it could reduce the incidence of CVP removal.

Key words : central venous access port device, bevacizumab, lung cancer 